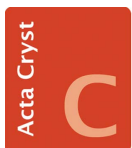

STRUCTURAL CHEMISTRY

ISSN 2053-2296

\title{
Acta Crystallographica Section $C$ is making an impact
}

\author{
Anthony Linden* \\ Department of Chemistry, University of Zurich, Winterthurerstrasse 190, CH-8057 Zürich, Switzerland. *Correspondence \\ e-mail: anthony.linden@chem.uzh.ch
}

Keywords: editorial; structural chemistry; NMR crystallography; scorpionates; impact; Scopus; CiteScore

Acta Crystallographica Section C STRUCTURAL CHEMISTRY

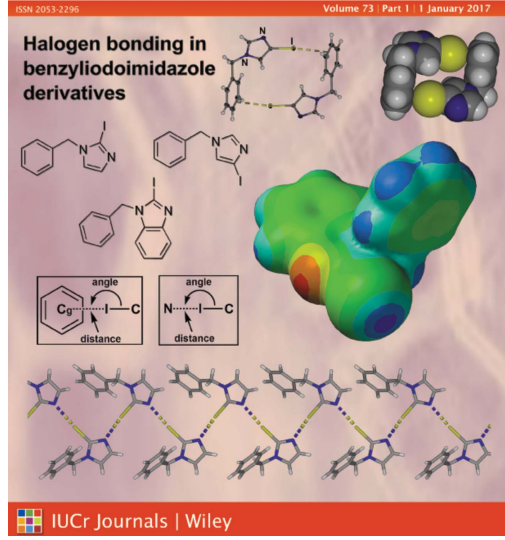

In my January 2015 editorial, I outlined the transformation that was in progress to bring Acta Crystallographica Section $C$ to the forefront of publishing in the broad field of structural chemistry. This evolution is progressing steadily and it is pleasing to see that an increasing number of papers include a broader spectrum of science in the discussion in addition to the crystal structure determinations. To re-emphasise my earlier comments: 'Section $C$ is the journal of choice for the rapid publication of articles that highlight interesting research facilitated by the determination, calculation or analysis of structures... Authors are encouraged to include mainstream science in their papers, thereby producing manuscripts that are substantial scientific well-rounded contributions that appeal to a broad community of readers and increase the profile of the authors.'

Our efforts on emphasising the new focus of the journal continue and we recently published a special issue on Scorpionates: a golden anniversary. I am most grateful to Glenn Yap (University of Delaware, USA) and Kiyoshi Fujisawa (Ibaraki University, Japan) for putting together this excellent collection of 16 papers. We will also publish a special issue on NMR Crystallography within the next few months. The guest editors, David Bryce (University of Ottawa, Canada) and Francis Taulelle (Université de Versailles Saint Quentin en Yvelines, France), are putting the finishing touches to this substantial special issue on what has become a very important field where the marriage of traditional crystallography with the results from solid-state NMR can be very powerful for structure elucidation.

I am pleased to announce that our efforts over the last three years, including the publication of feature articles, have already started to show a substantial increase in the journal's impact. This can be seen by looking at the Scopus CiteScore for the journal, which was 0.57 in 2015 and is showing an interim value of 3.56 for 2016 at time of writing. We hope that this will make the journal attractive to many new authors and readers and I invite you even now to submit your top papers to us to benefit from this development. Of course, raising the impact is only a start and we will be striving to sustain this by continuing to publish special issues on eminent topics, solicit feature articles of significant and general interest to those in the field of structural chemistry, as well as attracting scientific comments of appeal to the readership.

This is my final editorial as a Main Editor of Acta Crystallographica Section C. After the regulation nine-year term of office, it will be time to move on in August. Paul Raithby will continue as a Main Editor and the IUCr recently appointed two additional Main Editors: Larry Falvello (University of Zaragoza, Spain) and Jonathan White (University of Melbourne, Australia). I warmly welcome the new Main Editors and wish this able trio every success in the years ahead. I am also extremely grateful to the team of Co-editors, both current and past, for their support, dedication and energy over the last nine years and even beyond. The journal would not exist without their valued contributions. The hard work, support, friendship and congeniality of the Chester Editorial Office staff cannot be praised highly enough, as it is they who ultimately get the accepted papers through production into the final product that we all read. 